\title{
Is 6 Months of Antitubercular Chemotherapy as Effective as More Than 6 Months Regimen in Spinal Tuberculosis? A Systematic Review and Meta- analysis
}

\author{
Aayush $\operatorname{Aryal}^{1}$, Bhavuk Garg ${ }^{1}$, Nishank Mehta ${ }^{1}$, Shubhankar Shekhar ${ }^{1}$, Vivek Gupta ${ }^{2}$ \\ ${ }^{1}$ Department of Orthopaedics, All India Institute of Medical Sciences, New Delhi, India \\ ${ }^{2}$ Department of Community Ophthalmology, All India Institute of Medical Sciences, New Delhi, India
}

\begin{abstract}
Historically, osteoarticular tuberculosis (TB), including spinal TB, was treated with prolonged course of antitubercular therapy (ATT). Due to various challenges, there has been reluctance to explore the use of short-course ATT in spinal TB. However, with the success of short-course ATT being demonstrated in other forms of extrapulmonary TB, the subject is open for debate again. Therefore, we systematically reviewed various published literature to determine whether short-course treatment regimen (6 months) of ATT provides equivalent results in terms of disease healing as long-course treatment regimen ( $\geq 9$ months) in the management of spinal TB. Five electronic databases (PubMed, MEDLINE, EMBASE, CENTRAL, and Web of Science) and their reference lists were searched to identify relevant randomized controlled trials with at least 1 year of follow-up that compared short-course with standard-course ATT for treatment of spinal TB. The methodological quality of included studies was assessed, and their data were extracted. A meta-analysis was used to calculate pooled effect sizes and $95 \%$ confidence interval (CI). The outcome measure was healed status of the disease at the final follow-up. Of 331 publications identified through literature search, eight publications describing six randomized studies were included. Moreover, 375 of 414 patients $(90.58 \%)$ who received 6 months of ATT had healed status at their final follow-up compared to 404 of 463 patients $(87.26 \%)$ who received $\geq 9$ months of ATT. Overall, the healed status of spinal TB was equivalent in patients in both groups (pooled relative risk, $0.98 ; 95 \% \mathrm{Cl}, 0.92-1.04 ; p=0.439$ ). However, there was considerable heterogeneity among the trials (I $2=40.8 \%, p=0.149)$. The results suggest that the use of short-course ( 6 months) chemotherapy may be considered for the treatment of spinal TB in view of the similarity in the healing response achieved compared to treatment regimens of longer duration.
\end{abstract}

Keywords: Spinal tuberculosis; Pott's disease; Antitubercular drugs; Meta-analysis; Short course

\section{Introduction}

Tuberculosis (TB) is a leading cause of morbidity and mortality among all age groups, especially in developing countries [1]. Extrapulmonary TB (EPTB) comprises
$16.4 \%$ of the TB burden [2]. Skeletal TB is a major contributor to morbidity in children, adolescents, and young adults and consists of $10 \%-20 \%$ of the EPTB burden [3]. Spinal TB accounts for almost $50 \%$ of the total burden of skeletal TB [4]. According to the World Health Organiza-

Received Mar 24, 2021; Revised Apr 29, 2021; Accepted May 24, 2021

Corresponding author: Bhavuk Garg

Department of Orthopaedics, All India Institute of Medical Sciences, Room no. 139D, 1st Floor, Ansari Nagar, New Delhi, 110029, India

Tel: +91-9868397116, Fax: +91-11-26588919, E-mail: drbhavukgarg@gmail.com 
tion (WHO) database, the incidence of TB has increased in the last 4 decades to 10 million new cases annually in 2019 [1]. However, morbidity and mortality have decreased, which is attributable to the development and worldwide adoption of inexpensive and effective modern antitubercular therapy (ATT) [5]. Advances in imaging techniques and diagnostic tests have also led to an improvement in diagnosis, initiation, and optimization of treatment and follow-up of these patients.

Most existing resources for research, diagnosis, and treatment of $\mathrm{TB}$ have been aimed at pulmonary $\mathrm{TB}$ - as this is overwhelmingly the most commonly encountered form of TB and, due to its mechanism of transmission, has been considered more important for public health and $\mathrm{TB}$ control. The low incidence rates of spinal TB in developed countries and poor data reporting with lack of nationalscale registries for spinal TB in developing countries have made it difficult to generate high-quality evidence to provide recommendations regarding appropriate treatment duration in spinal TB. This is augmented by the fact that it is difficult to conclusively document healing of spinal TB. The conventional practice of providing long-course treatment regimens for spinal TB has been based on the poor penetration of antitubercular drugs in the bone, possible blunting action in closed anoxic conditions due to acidic microenvironment found in spinal TB lesions and the potentially devastating course of disease if left partially treated [6-8]. Ideally, the only conclusive method of documenting healed disease would be vertebral biopsywhich is not feasible in a practical scenario considering that repeated biopsies may be needed and diagnostic yield of a biopsy may be poor. The paucibacillary nature of spinal TB makes it difficult to accurately label the disease as "healed". A combination of various tests (clinical response, radiological response on plain radiography or magnetic resonance imaging [MRI], and inflammatory markers such as C-reactive protein [CRP]) may improve the accuracy of "healing criteria". Therefore, in common practice, clinical and radiological resolution at the completion of ATT with no disease relapse at a 2-year follow-up is defined as healed status [9-13].

Considering the aforementioned challenges in spinal $\mathrm{TB}$, to date, there has been reluctance to explore the use of short-course antitubercular chemotherapy in spinal TB. However, with the success of short-course ATT in other forms of EPTB $[14,15]$ and recent evidence suggesting the same in spinal TB $[16,17]$, the subject is open for debate again. Reaching a global consensus on the ideal treatment duration in spinal TB is important. Longer duration of administration than necessary tends to prolong the exposure to side effects and places a burden on either the patient's pockets or public health spending, depending on the healthcare system of each country. Conversely, shorter durations risk inadequate disease healing with its attendant complications, such as progression of deformity or development of neurological deficit, and would also contribute to drug resistance.

Therefore, we reviewed various published literature for the recommended duration of chemotherapy in spinal TB. This study aimed to determine whether a shorter course of chemotherapy (6 months) provide equivalent results in terms of healing of the disease as the standard duration of chemotherapy ( $\geq 9$ months) in the treatment of spinal TB.

\section{Materials and Methods}

A protocol for conducting this review was registered in PROSPERO on August 24, 2020 (registration no., CRD42020200938) [18]. We followed the PRISMA (Pre-

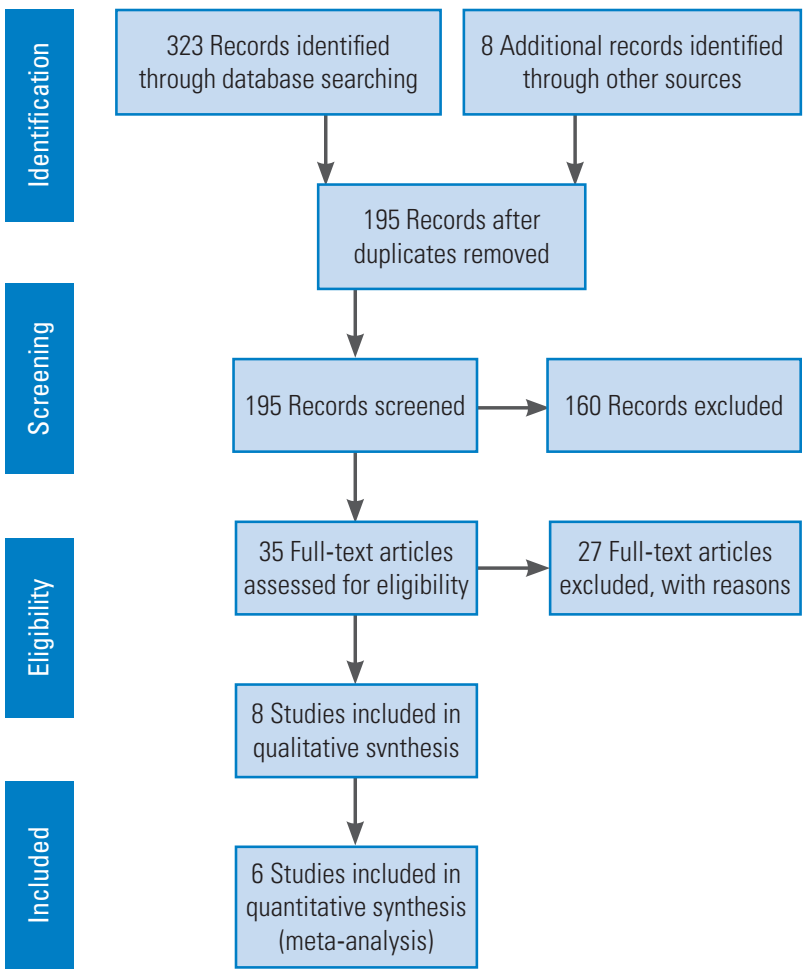

Fig. 1. Flowchart outlining the systematic review process in accordance to the PRISMA (Preferred Reporting Items for Systematic Reviews and MetaAnalyses) guidelines (2009). 
ferred Reporting Items for Systematic Reviews and MetaAnalyses) 2009 guidelines, outlined in Fig. 1.

\section{Eligibility criteria}

We included studies that described adults or children with primary, drug-sensitive spinal TB (single level or multilevel) who received drug treatment with at least isoniazid and rifampicin for spinal TB and whose healing status was assessed at the endpoint of therapy or during the followup period. Only randomized controlled trials (RCTs) comparing short-course chemotherapy with standardcourse ( $\geq 9$ months) chemotherapy, with a follow-up period of at least 12 months after completion of chemotherapy, were included. Studies published between 1980 and 2019, in the English language originally and those available with English translation, were included. Studies on patients who had known multi-drug resistant (MDR) and extremely drug-resistant TB, who had received secondline ATT, and in whom healing/resolution of disease at the endpoint of therapy or during the specified follow-up period had not been reported were excluded. Moreover, nonrandomized prospective studies, retrospective studies, case reports, case series, and review articles were excluded. All unrelated studies, duplicated studies, abstractonly papers, and articles without available full text were excluded.

\section{Search strategy}

We performed a thorough search of the electronic databases to identify RCTs performed on humans on PubMed (1968-2020), MEDLINE (1968-2020), EMBASE (19542020), The Cochrane Central Register of Controlled Trials (CENTRAL) (1954-2020), and Web of Science (1956-2020). The last search date was August 25, 2020. Search strategies included a combination of various freetext terms and appropriate subject indexing (e.g., Medical Subject Headings [MeSH], such as tuberculosis spine, TB spine, Pott's disease, spinal tuberculosis, chemotherapy, antitubercular therapy, duration, course, short-course, and clinical trial).

\section{Data abstraction and management}

All records were collected into a reference manager library. After the removal of duplicates, two independent reviewers (A.A. and S.S.) screened the titles and abstracts of all selected articles to decide which ones to include. Any disagreement regarding inclusion/exclusion of a study was resolved through discussion and consensus or by consultation with the senior author (B.G.). Moreover, the reference lists of key articles identified during the search were screened for additional relevant articles. The second round of screening was conducted by reviewing the full-text articles of selected studies. The list of excluded studies with the reasons for omission is presented in Table 1 [13,19-44].

\section{Assessment of methodological quality}

The risk of bias of each included RCT was assessed using the adapted GRADE (Grading of Recommendations Assessment, Development and Evaluation) approach with the 11-point criteria as recommended by the Cochrane Back Review Group [45]. Only studies that adequately fulfilled $50 \%(6 / 11)$ or more of the validity criteria were considered to have low risk of bias (Table 2) [16,17,46-49]. The two authors resolved disagreements in the assessment of the risk of bias by consensus.

\section{Data extraction, synthesis, and analysis}

A data extraction form was created in Excel, and data were entered into the spreadsheets. Data collected on each study included basic information on the study, including research title, first author, publication year, study type, sample size, demographic characteristics, affected areas of the spine, chemotherapeutic regimen used, duration of administration, inclusion and exclusion criteria, criteria for healing, and healing rate. Various studies used a variable combination of outcome measures, such as symptomatic relief, neurological recovery, subsidence of abscesses/ sinuses, normalization of erythrocyte sedimentation rate or CRP level, and radiographic and/or MRI changes suggestive of resolution with no signs of relapse on follow-up.

\section{Statistical methods}

The meta-analysis was conducted using Stata ver. 15.2 (Stata Corp., College Station, TX, USA). The randomeffects model using the DerSimonian and Laird method was used to calculate pooled effect sizes and its 95\% confidence interval (CI) limit with the help of the METAN 
Table 1. Studied excluded from the systematic review after reviewing the full-text

\begin{tabular}{|c|c|}
\hline Study & Reason for exclusion \\
\hline Abbas et al. [19] (2013) & All patients received 12 months of ATT \\
\hline Bakhsh [20] (2010) & Only discusses about the diagnosis of spinal tuberculosis \\
\hline Batirel et al. [21] (2015) & No comparison between short vs standard course chemotherapy \\
\hline Bodapati et al. [22] (2017) & Duration of ATT not clear, no comparative groups \\
\hline Cao et al. [23] (2018) & All patients received 18 months of ATT \\
\hline Guo et al. [24] (2010) & No comparison between short vs. standard course chemotherapy \\
\hline Jain et al. [25] (2012) & No comparison between short vs. standard course chemotherapy \\
\hline Jutte et al. [26] (2006) & No comparison between short vs. standard course chemotherapy \\
\hline Karaeminogullari et al. [27] (2007) & No comparison between short vs. standard course chemotherapy \\
\hline Kotil et al. [28] (2007) & All patients received 15-18 months of ATT \\
\hline Mittal et al. [13] (2019) & No randomization; wide variability in the duration of chemotherapy \\
\hline Moon et al. [29] (1987) & No comparison between short vs. standard course chemotherapy \\
\hline MRC [30] (1998) & No details about the short vs. standard course RCTs. Mainly discusses about the other MRC trials (e.g., POP jacket, debridement, etc.) \\
\hline Niu et al. [31] (2017) & No comparison between short vs. standard course chemotherapy \\
\hline Parthasarathy et al. [32] (1999) & 10-Year follow-up of MRC Madras study, with greater loss of follow-up \\
\hline Patankar [33] (2016) & No comparison between short vs. standard course chemotherapy \\
\hline Patil et al. [34] (2014) & All patients received 12 months of ATT \\
\hline Qian et al. [35] (2016) & No comparison between short vs. standard course chemotherapy \\
\hline Rajasekaran et al. [36] (1998) & Did not discuss the duration of AT;; Also, the sample overlaps with the MRC Madras study \\
\hline Rajeswari et al. [37] (1997) & No comparison between short vs. standard course chemotherapy \\
\hline Upadhyay et al. [38] (1996) & Data on healing/final outcome not clearly stated in results \\
\hline Valsalan et al. [39] (2012) & No comparison between short vs. standard course chemotherapy \\
\hline Wang et al. [40] (2007) & Excluded as this is a subset of the Wang et al. [41] (2013) study \\
\hline Wang et al. [41] (2013) & Retrospective study; no comparison between short course and standard chemotherapy \\
\hline Wardak et al. [42] (2014) & Duration of ATT not clear; no comparative groups \\
\hline Wu [43] (1990) & No comparison between short vs. standard course chemotherapy \\
\hline Zhang et al. [44] (2013) & No comparison between short vs. standard course chemotherapy \\
\hline
\end{tabular}

ATT, anti-tubercular therapy; RCT, randomized controlled trial; MRC, Medical Research Council; POP, plaster of Paris.

command [50,51]. Forest plots were generated, displaying the proportion of patients with resolution of the disease, with corresponding $95 \%$ CI. We examined the variation in the magnitude of effect and quantified the heterogeneity using $I^{2}$ statistic. No subgroup analysis was conducted.

\section{Results}

\section{Study selection}

The search yielded 323 articles, and additional eight relevant articles were identified by going through the references of these searched articles. After removing 128 dupli- cations, the titles and abstracts of 195 articles were further screened for relevance based on the inclusion and exclusion criteria. A total of 35 full-text articles were assessed for eligibility, of which eight publications, discussing six trials (the other two were follow-up studies of two of these trials), were included in the systematic review [16,17,46$49,52,53]$. The six randomized trials compared groups of patients receiving antitubercular chemotherapy at different durations. Five of these studies were RCTs, and one was described as a prospective randomized study. Three of the trials were part of the British Medical Research Council (MRC) Working Party on Tuberculosis of the Spine series (one of them in coordination with the Indian Council 
Table 2. Assessment of methodological quality of the 6 trials on the basis of the Cochrane Back Review Group 11 points criteria

\begin{tabular}{|c|c|c|c|c|c|c|}
\hline \multirow[b]{2}{*}{ Variable } & \multicolumn{6}{|c|}{ Study } \\
\hline & MRC [46] & MRC [47] & MRC [48] & $\begin{array}{l}\text { Wang et } \\
\text { al. [16] }\end{array}$ & $\begin{array}{l}\text { Banga et } \\
\text { al. [49] }\end{array}$ & $\begin{array}{l}\text { Nene et al. } \\
\text { [17] }\end{array}$ \\
\hline Year of publication & 1986 & 1993 & 1989 & 2013 & 2018 & 2019 \\
\hline \multicolumn{7}{|l|}{ Criteria } \\
\hline Was the randomization adequate? & Yes & Not sure & Yes & Yes & Not sure & Yes \\
\hline Was the treatment allocation concealed? & Yes & Not sure & Yes & Yes & Not sure & Not sure \\
\hline Were the groups similar at baseline regarding the most important prognostic indicators? & Yes & Yes & Yes & Yes & Not sure & Yes \\
\hline Were the patients blinded? & Not sure & Not sure & Not sure & Not sure & No & No \\
\hline Was the care provider blinded? & Not sure & Not sure & Not sure & Not sure & Not sure & No \\
\hline Was the outcome assessor blinded? & Not sure & Not sure & Not sure & Not sure & Not sure & Not sure \\
\hline Were cointerventions avoided or similar? & Yes & Yes & Yes & Yes & Yes & Yes \\
\hline Was the compliance acceptable in all groups? & Yes & Yes & Yes & Yes & Yes & Yes \\
\hline Was the drop-out rate described and acceptable? & Yes & Yes & Yes & Yes & Yes & Yes \\
\hline Was the timing of the outcome assessment in all groups similar? & Yes & Yes & Yes & Yes & Yes & Yes \\
\hline Did the analysis include an intention-to-treat analysis? & Yes & Yes & Yes & Yes & Yes & Yes \\
\hline Total score & 8 & 6 & 7 & 7 & 5 & 7 \\
\hline
\end{tabular}

MRC, Medical Research Council.

of Medical Research). These studies were conducted in Hong Kong, Korea, and India in the 1970s and 1980s on patients with spinal TB and showed results at 3 years of follow-up [46-48]. Two additional publications (one was a 5-year follow-up report of all three aforementioned trials reported together, and the other was a 5-year followup report of the MRC 1989 trial) were reviewed [52,53]. The next one was a prospective randomized study, where patients were randomized by allowing them to extract envelopes that had random numbers [16]. The last two studies were recent RCTs from India [17,49]. The 5-year follow-up data for Korea (MRC 1993) reported in the MRC 1999 paper was not included in the analysis as there was a considerable dropout rate at 5 years; hence, only the 3-year follow-up data of this study are presented here [52].

\section{Study characteristics}

1) Inclusion, exclusion, diagnostic, and healing criteria All studies included patients with clinical and radiological evidence of spinal TB. Since the MRC trials were conducted in the pre-MRI era, only plain radiographs of the spine were used in the diagnosis, in addition to the clinical features $(n=723)$. However, the other three studies included MRI in making the diagnosis $(\mathrm{n}=315)$. The trial by Nene at al. [17] routinely used computed tomography (CT)guided biopsy in confirming the diagnosis of all patients included in their study $(\mathrm{n}=100)$.

The MRC trials included patients with TB affecting the first thoracic to first sacral vertebrae only. However, the other three studies did not restrict their inclusion criteria to the thoracolumbar region and included cases of cervical and sacral TB. The MRC trials excluded patients with serious extraspinal disease, which was likely to affect their management or response to treatment; patients who received ATT for $\geq 12$ months, patients with severe paraplegia, and those who already underwent surgery for spinal TB. Wang et al. [16] excluded patients who had any contraindication to surgical intervention. Banga et al. [49] and Nene et al. [17] excluded patients with a history of ATT administration and those with MDR TB.

The MRC trials considered clinical and radiological resolution (on anteroposterior and lateral radiographs of the spine) as the criteria for healing. Clinical resolution was defined as resolution of patient's symptoms (decrease in pain, improvement in neurological status, absence of constitutional symptoms, weight and appetite gain, and healing of discharging sinuses, if any), and radiological resolution was defined as decrease in fuzziness of endplate or sclerosis, fusion of adjacent vertebrae, sharpening of 


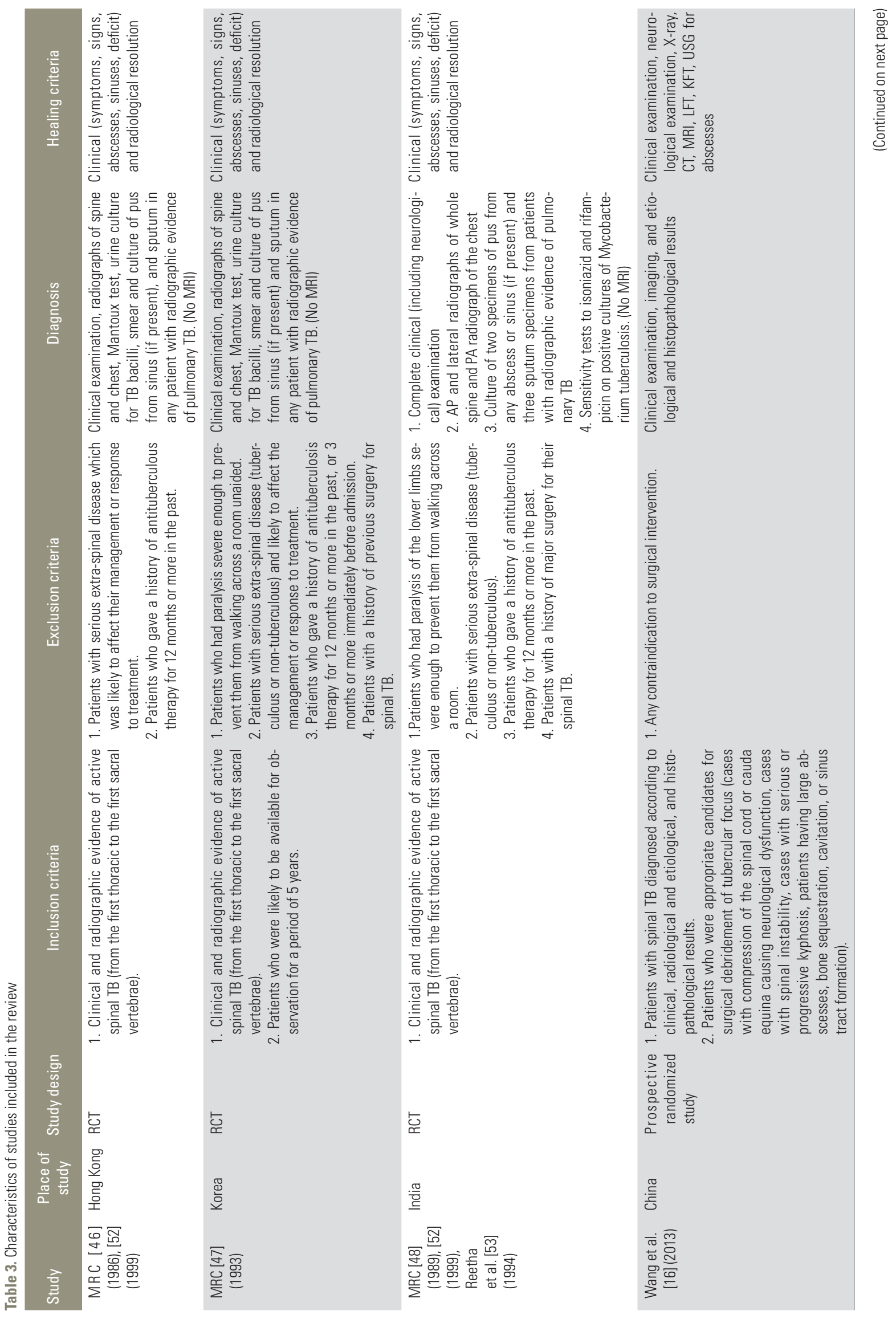




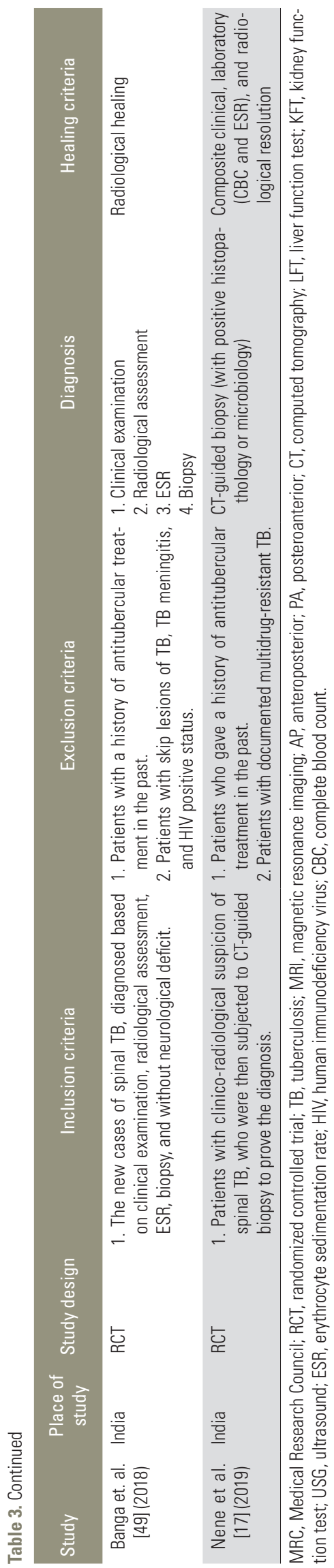

cortical margins, remineralization, and revisualization of bony trabeculae. Wang et al. [16] and Nene et al. [17] considered composite clinical, laboratory, and radiological factors (plain radiography, CT, and MRI) in declaring the disease of a patient as healed. The signs of resolution on CT were similar to those on plain radiographs. The MRI criteria they used were decreased bone marrow edema, decreased soft tissue collections, decreased subligamentous spread, and fatty replacement of the marrow seen as hyperintensity on T1 and T2-weighted images and/or lack of contrast enhancement on post-gadolinium MRI. Banga et al. [49] only considered radiological resolution (plain radiography and MRI) in declaring a patient healed and did not discuss whether they also considered clinical improvement. The detailed criteria used in the individual studies are shown in Table 3 [16,17,46-49,52,53].

\section{2) Characteristics of the participants}

A total of 1,038 patients were enrolled in the six studies. Demographic and important clinical data of these six studies are summarized in Table $4[16,17,46-49,52,53]$. A total of 158 patients were excluded from the MRC studies during the analysis of healing at the final follow-up due to various reasons, such as change in the diagnosis during surgery due to growth of pyogenic organism on culture of operative specimen, absence of evidence of tuberculous lesion during surgery, healed spinal lesion during surgery, modification of chemotherapy due to toxicity, treatment default or loss of follow-up, and death due to mostly nontuberculous causes. Three patients from the study by Banga et al. [49] were excluded due to loss of follow-up. All patients in the two remaining studies completed the required follow-up. The MRC studies did not specify the average age and sex distribution in their patients; however, almost half of patients included in these three MRC trials were aged $<15$ years. The age and sex distribution of the three remaining studies are demonstrated in Table 4.

Most patients had tuberculous lesion in the lumbar and lumbosacral spine $(n=392)$, followed by those in the thoracic spine $(n=288)$, thoracolumbar spine $(n=162)$, cervical spine $(n=17)$, cervicothoracic spine $(n=10)$, multifocal $(n=7)$, and sacral spine $(n=1)$. In the MRC trials, no patient had severe paraplegia, but 53 patients had some neurological deficit at admission. Moreover, 54 patients in the trial by Wang et al. [16] and 27 patients in the trial by Nene et al. [17] had some form of neurological deficit. Although the presence of drug resistance was an exclu- 
Table 4. Demographic and relevant clinical data of the six studies included in the review

\begin{tabular}{|c|c|c|c|c|c|c|}
\hline Study & $\begin{array}{l}\text { Sample } \\
\text { size at } \\
\text { enrolment }\end{array}$ & Age & Gender & Area of the spine affected & $\begin{array}{l}\text { Neurologic } \\
\text { deficit }\end{array}$ & Drug resistance \\
\hline $\begin{array}{l}\text { MRC [46] (1986), } \\
\text { [52] (1999) }\end{array}$ & 60 & $\begin{array}{l}<15 \text { yr (13); } 15-54 \text { yr (28); } \\
\quad \geq 55 \text { yr (9) }\end{array}$ & Not specified & $\begin{array}{l}\text { Thoracic (18), thoracolumbar (4), lum- } \\
\text { bar/lumbosacral (28) }\end{array}$ & 3 & $\begin{array}{l}6 \text { of the } 43 \text { patients' } \\
\text { operative samples } \\
\text { tested were resis- } \\
\text { tant for } 1 \text { drug }\end{array}$ \\
\hline MRC [47] (1993) & 359 & $\begin{array}{l}0-4 \text { yr (78); } 5-14 \text { yr }(68) ; \\
15-34 \text { yr (76); 35-54 yr } \\
(40) ; \geq 55 \text { yr (3) }\end{array}$ & Not specified & $\begin{array}{l}\text { Thoracic (94), thoracolumbar (58), lum- } \\
\text { bar (78), lumbosacral (35) }\end{array}$ & 33 & Not mentioned \\
\hline $\begin{array}{l}\text { MRC [48] (1989), } \\
\text { [52] (1999), } \\
\text { Reetha et al. } \\
\text { [53](1994) }\end{array}$ & 304 & $\begin{array}{l}<15 \text { yr (84); 15-54 yr (158); } \\
\quad \geq 55 \text { yr (8) }\end{array}$ & Not specified & $\begin{array}{l}\text { Thoracic (93), thoracolumbar (33), lum- } \\
\text { bar and lumbosacral (124) }\end{array}$ & 17 & Not mentioned \\
\hline $\begin{array}{l}\text { Wang et al. [16] } \\
\text { (2013) }\end{array}$ & 185 & $\begin{array}{l}\text { USCC group: } 37.96 \pm 16.30 \text { yr; } \\
\text { StdCC group: } 41.53 \pm 15.76 \\
\text { yr }\end{array}$ & $\begin{array}{l}\text { USCC (M=54, F=42); StdCC } \\
\qquad(M=50, F=39)\end{array}$ & $\begin{array}{l}\text { Cervical (7), cervicothoracic (3), thoracic } \\
\text { (38), thoracolumbar (42), lumbar (72), } \\
\text { lumbosacral (23) }\end{array}$ & $\begin{array}{l}54 \text { (30/96 and } \\
\text { 24/89) }\end{array}$ & 5 Cases of MDR TB \\
\hline $\begin{array}{l}\text { Banga et. al. [49] } \\
\text { (2018) }\end{array}$ & 30 & $\begin{array}{l}0-20 \text { yr (3); } 21-40 \text { yr (14); } \\
>40 \text { y (10) }\end{array}$ & $M(15), F(12)$ & $\begin{array}{l}\text { Cervical (2), thoracic (14), thoracolum- } \\
\text { bar (3), lumbar (8) }\end{array}$ & $\begin{array}{l}\text { None were } \\
\text { included }\end{array}$ & $\begin{array}{l}\text { None (excluded if } \\
\text { known) }\end{array}$ \\
\hline $\begin{array}{l}\text { Nene et al. [17] } \\
\text { (2019) }\end{array}$ & 100 & $\begin{array}{l}\text { SCC group: } 36.5 \text { yr (range, } \\
\text { 12-71 yr); StdCC group: } 52 \\
\text { yr (range, } 16-91 \text { yr) }\end{array}$ & $\begin{array}{l}\operatorname{SCC}(\mathrm{M}=26, \mathrm{~F}=26) ; \mathrm{StdCC} \\
(\mathrm{M}=23, \mathrm{~F}=25)\end{array}$ & $\begin{array}{l}\text { Cervical (8), cervicothoracic (7), thoracic } \\
\text { (31), thoracolumbar (22), lumbar (21), } \\
\text { lumbosacral (3), sacral (1), multifocal } \\
\text { (7) }\end{array}$ & $27 / 100$ & $\begin{array}{l}\text { None (excluded if } \\
\text { known) }\end{array}$ \\
\hline
\end{tabular}

MRC, Medical Research Council; USCC, ultra-short-course chemotherapy; StdCC, standard-course chemotherapy; M, male; F, female; MDR TB, multi-drug resistant tuberculosis; SCC, short-course chemotherapy.

sion criterion in all these studies, in the MRC 1986 trial in Hong Kong, the operative samples in six of 43 patients were resistant to one of the drugs, and five patients in the study by Wang et al. [16] were found to have MDR on samples obtained during surgery.

\section{3) Results of individual studies}

All six studies used different regimens of ATT, with at least isoniazid and rifampicin/ethambutol in all these regimens. The duration of ATT varied from as short as 4 to 18 months $[16,47]$. All drugs were administered orally, except streptomycin, which was administered via the intramuscular route. All cohorts received ATT dosage according to patients' weight. Intermittent regimen (thrice weekly) was administered in only one study in the intervention group (6-month directly observed therapy short course) [49]. All other studies provided daily regimen. The regimens used, duration in their respective cohorts, number of individuals in each group assessed at the final follow-up, and number of patients declared to have disease resolution at that time, with their follow-up duration, are presented in Table $5[16,17,46-49,52,53]$. Surgical intervention was conducted in all patients in the MRC 1986 trial $(\mathrm{n}=50)$ and trial by Wang et al. [16] $(\mathrm{n}=185)$ and in the Rad 6 group of the MRC 1989 trial $(n=82)$; no patient underwent surgery in the MRC 1993 trial; and only those patients with surgical indications underwent surgery with or without spinal instrumentation in the studies by Banga et al. [49] ( $\mathrm{n}=$ unspecified) and Nene et al. [17] $(\mathrm{n}=46)$. No patient in any of the six trials had disease relapse till their final follow-up. The mean follow-up duration varied from 15 to 87 months across the studies.

All cohorts in the six studies reported reasonable healing rates except one [47]. Only the results of MRC 1993 (specifically the $9 \mathrm{H}+\mathrm{P} / \mathrm{E}$ regimen) were clearly inferior compared to all other cohorts of the included studies. In the meta-analysis, cohorts receiving 6-month regimen in each trial were pooled into the "intervention" arm, and cohorts in all trials receiving ATT for 9-18 months were pooled into the "control" arm. The trial by Nene et al. [17] reported a $100 \%$ healing rate in both groups, that is, no unfavorable outcome (no events in both groups). Therefore, it had no (i.e., zero) weight in the pooled analysis and was excluded from the forest plot. The analysis was conducted based on the healing rate in patients assessed at the final follow-up. Moreover, $90.58 \%$ (375/414) of pa- 


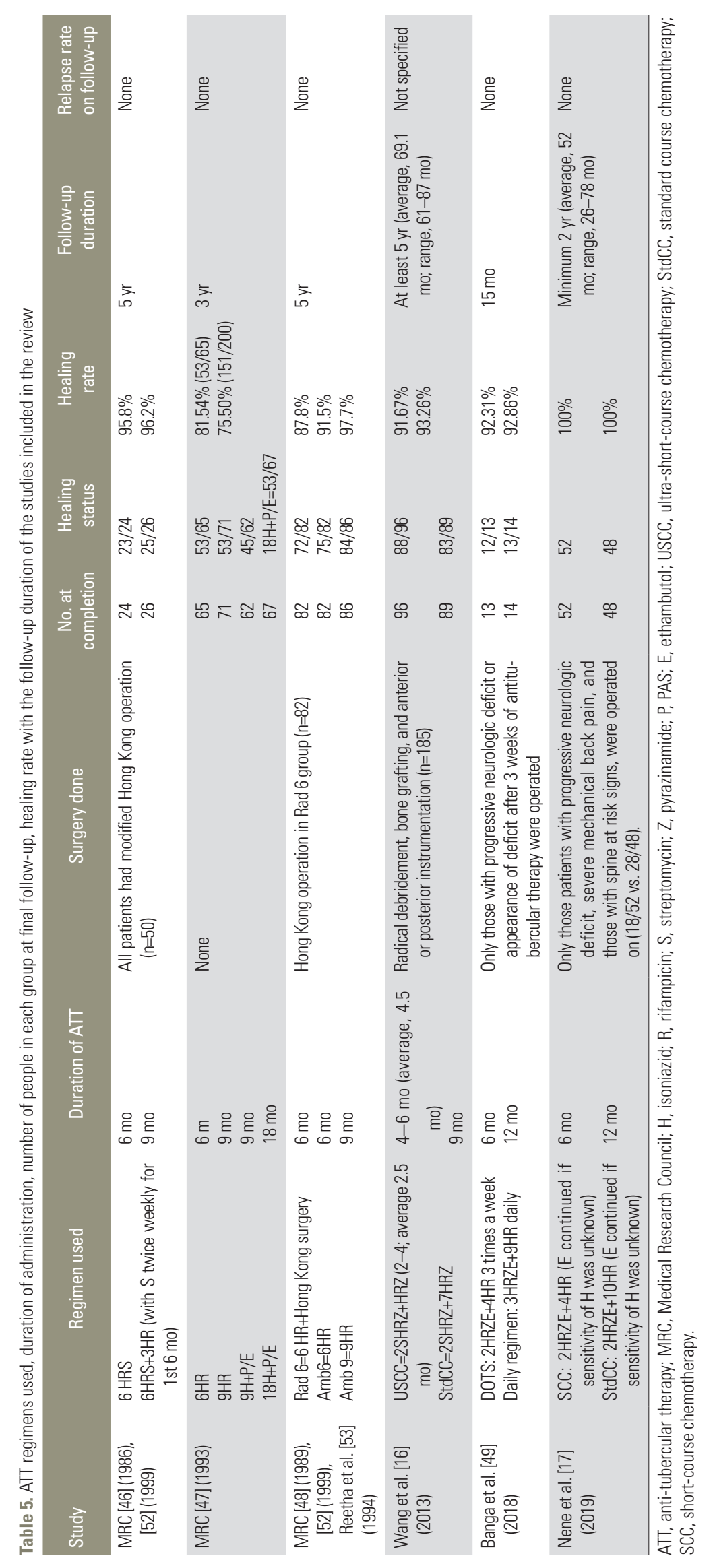


Table 6. Healing status at final follow-up

\begin{tabular}{|c|c|c|c|c|c|c|c|c|c|}
\hline \multirow{2}{*}{ No. } & \multirow{2}{*}{ Study } & \multirow{2}{*}{ Country } & \multicolumn{3}{|c|}{ Short course chemotherapy } & \multicolumn{3}{|c|}{ Conventional chemotherapy } & \multirow{2}{*}{$\begin{array}{l}\text { Relative } \\
\text { risk }\end{array}$} \\
\hline & & & No. & Improved & Risk & No. & Improved & Risk & \\
\hline 1 & MRC [52] (1999) & Hong Kong & 24 & 23 & 0.96 & 26 & 25 & 0.96 & 1.00 \\
\hline 2 & MRC [47] (1993) & Korea & 65 & 53 & 0.82 & 200 & 151 & 0.75 & 1.08 \\
\hline 3 & MRC [52] (1999), Reetha et al. [53] (1994) & India & 164 & 147 & 0.90 & 86 & 84 & 0.98 & 0.92 \\
\hline 4 & Wang et al. [16] (2013) & China & 96 & 88 & 0.92 & 89 & 83 & 0.93 & 0.98 \\
\hline 5 & Banga et. al. [49] (2018) & India & 13 & 12 & 0.92 & 14 & 13 & 0.93 & 0.99 \\
\hline \multirow[t]{2}{*}{6} & Nene et al. [17] (2019) & India & 52 & 52 & 1.00 & 48 & 48 & 1.00 & 1.00 \\
\hline & Total & & 414 & 375 & - & 463 & 404 & - & - \\
\hline
\end{tabular}

MRC, Medical Research Council.

\section{Outcomes among followed-up patients}

\begin{tabular}{|c|c|c|}
\hline Study ID & $\mathrm{RR}(95 \% \mathrm{Cl})$ & Weight (\%) \\
\hline MRC [52] (1999) (Hong Kong) & $1.00(0.89-1.12)$ & 18.53 \\
\hline MRC [47] (1993) (Korea) & $1.08(0.94-1.24)$ & 13.87 \\
\hline MRC [52] (1999) (India) & $0.92(0.86-0.98)$ & 33.92 \\
\hline Wang et al. [16] (2013 (China) & $0.98(0.91-1.07)$ & 26.66 \\
\hline Banga et al. [49] (2018) (India) & $0.99(0.80-1.23)$ & 7.02 \\
\hline Nene et al. [17] (2019) (India) & Excluded & 0.00 \\
\hline Overall $\left(P^{2}=40.8 \%, p=0.149\right)$ & $0.98(0.92-1.04)$ & 100 \\
\hline 0.803 & & \\
\hline
\end{tabular}

Fig. 2. Forest plot of the relative risk (RR) of successful outcome with 6 months regimen and more than 6 months regimen. The center of the squares and the horizontal line represent estimated RR and 95\% confidence interval (CI) of each included study respectively. The diamond represents the summary RR and $95 \% \mathrm{Cl}$. Heterogeneity and overall effect are given on the left side of the summary statistics. Weights are from random effects analysis. $P^{2}=$ percentage of total variation across the studies that is the result of heterogeneity rather than chance.

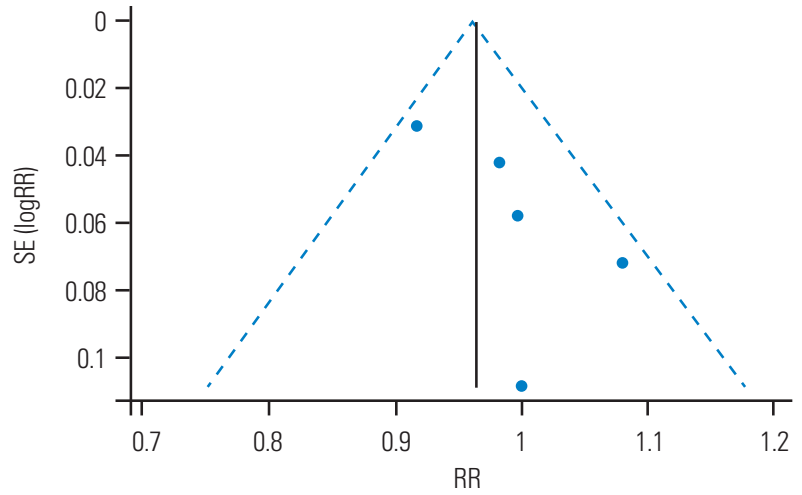

Fig. 3. Funnel plot for outcomes among followed-up patients. RR, relative risk; SE, standard error.

tients who received 6 months of ATT had healed status at their final follow-up compared to $87.26 \%(404 / 463)$ of patients who received $\geq 9$ months of ATT (Table 6) $[16,17,47,49,52,53]$.
Overall, the healed status of spinal TB was equivalent among patients in both 6 months and $>6$ months group (pooled relative risk [RR], 0.98; 95\% CI, 0.92-1.04; test of $\mathrm{RR}=1, z=0.77, p=0.439$ ) (Figs. 2, 3) $[16,17,47,49,52]$. There was a considerable heterogeneity among the trials $\left(I^{2}=40.8 \%\right)$, which was not statistically significant (heterogeneity chi-square $=6.76$; degrees of freedom $=4 ; p=0.149$ ). The test of heterogeneity is poor at detecting true heterogeneity in meta-analyses such as this one, which includes a small number of studies. Therefore, the power of the test in such circumstances is low [54]. Because the test of heterogeneity, in this case, is poor in detecting true heterogeneity, a nonsignificant $p$-value should not be taken as evidence of homogeneity [55].

\section{Discussion}

Over the past few decades, antitubercular chemotherapy 
has emerged as the cornerstone in the management of spinal TB. With successful outcomes being demonstrated by ambulatory chemotherapy, the indications for surgical intervention in spinal TB have decreased; for most surgeons, these indications include severe paraplegia at presentation, progressive neurological deficit while on treatment, progressive deformity, persistent back pain due to mechanical instability, and lack of clinical response to chemotherapy. Chemotherapy alone for the treatment of spinal TB has several advantages, including ambulatory treatment, avoidance of hospital stay, avoidance of morbidity related to surgery, and cost-effectiveness. The developed and developing countries are at dramatically different stages in their fight against $\mathrm{TB}$, which has led to a difference in the priority given to TB as a public health problem by different countries. Due to this relative lack of large, multicenter studies, there is a lack of consensus about the appropriate duration of administration of ATT in spinal TB.

There is a wide variation in the duration of ATT advocated for spinal TB by the guidelines of various national and international societies. This ranges from 6 to 18 months. The British MRC guidelines suggest multi-drug combination chemotherapy for 6-9 months for the treatment of TB of the dorsolumbar spine [56]. The limitations of the research council's studies were the exclusion of patients with multiple vertebral involvement, TB of the cervical spine, and major neurologic deficit. The National Institute for Health and Care Excellence guidelines and the WHO recommend 6 months and 9 months of treatment, respectively, for spinal TB $[57,58]$. Similarly, the American and the Canadian Thoracic Societies recommend 6-9 months and 9-12 months of treatment, respectively $[58,59]$. While there is a certain amount of discrepancy even in these standard guidelines (range, 6 to 12 months), all these guidelines are from developed countries with low disease burden. In developing countries, there are still no national consensus guidelines that specifically mention the treatment duration for spinal TB. In addition to spine surgeons (orthopedicians or neurosurgeons), spinal TB in these high-burden countries is also commonly treated by physicians, infectious disease specialists, or pulmonologists. This results in great heterogeneity in treatment, leading to lack of standardization of treatment duration at the national and international levels. The common practice of continuing treatment until completion of radiological healing may be unnecessary-since radiological healing has been believed to lag behind clinical response [60]. The long track record of short-course chemotherapy in pulmonary $\mathrm{TB}$ and its recently reported success in several forms of EPTB have led to the emergence of calls for short-course regimens to be investigated for spinal TB.

In a bid to compile the understanding that can be gleaned from existing evidence, we performed a metaanalysis of all prospective RCTs comparing short-course antitubercular chemotherapy with treatment regimens of longer durations, which met our well-defined inclusion criteria. Our meta-analysis shows that 6-month regimen of ATT is equivalent to the standard 9-18-month regimen in terms of clinical and radiological disease resolution, although there was considerable heterogeneity among the trials. In these studies, clinical and radiological resolution were used to determine the endpoint of treatment. There have been systematic reviews and meta-analyses in the literature that have compared chemotherapy alone to chemotherapy with surgical intervention in spinal TB $[26,44]$. Moreover, van Loenhout-Rooyackers et al. [61] performed a literature review in 2002 that evaluated whether 6 months of ATT was good enough to prevent relapse as effectively as more than 6 months of ATT in spinal TB. To the best of our knowledge, this is the first meta-analysis that compared the effectiveness of 6-month regimen of ATT with the standard 9-18-month regimen in spinal TB.

There are some limitations to this review. First, there was a paucity of literature comparing the shorter courses with the longer duration of ATT. Importantly, high-quality RCTs were lacking in this area. This was a reason that only six studies were included in our review. Second, the follow-up data reported in the MRC 1999 publication for the MRC 1993 (Korea) trial were inadequate. Third, MRC trials were performed nearly 4 decades ago. Therefore, the current clinical relevance of these trials is difficult to determine, given the advances in management with fourdrug ATT and surgery for spinal TB. Fourth, there was considerable heterogeneity in the presentation of results across the studies, including a lack of reporting of sex distribution in the MRC trials. Lastly, there is a gap in the timeline between the selected studies: the MRC trials were conducted in the 1970s and 1980s, while the three remaining studies were conducted within the last decade. This led to a discrepancy in the healing criteria between these two different groups of studies, as the MRC trials were conducted in the pre-MRI era and thus the resolution of disease activity and relapses could not be assessed 
by MRI in patients included in these trials, which form the majority of the sample size of our review. The co-interventions were dissimilar in some comparative groups as surgery was more commonly offered to patients receiving shorter duration of chemotherapy (317 of 414 patients in the 6-month course group were routinely offered radical debridement surgery), which may have been a confounding factor, leading to better results with shorter course of ATT as the reduction of disease burden during surgery for spinal TB is believed to promote early radiological fusion and quick relief of symptoms in patients. However, evidence suggests that routine surgery in addition to chemotherapy does not necessarily improve the prognosis of patients with spinal TB [26]. Nevertheless, we still divided the cohorts in the six studies into two groups and did a comparison in the healing rate between them.

\section{Conclusions}

The six trials comparing short-course treatment regimens (6 months) to longer regimens ( $\geq 9$ months) show no significant difference in the healing or disease resolution. However, a considerable number of patients receiving 6-month regimen underwent routine surgery, which could be a major confounding factor. This study echoes the widely recognized principle of medical treatment being the first-line management for spinal TB. The existing evidence from the studies included in this meta-analysis-although not without its limitations-suggests that the use of short-course (6 months) chemotherapy may be considered for the treatment of spinal TB in view of the similarity in the healing response achieved compared to treatment regimens of longer duration. If a shorter course of antitubercular chemotherapy could be adopted in clinical practice for spinal TB, it would contribute to improved patient compliance, decrease the cost, and minimize the side effects of these medications. However, we emphasize the need to be watchful for disease relapse until definitive conclusions can be drawn based on more prospective RCTs recruiting a larger study population.

\section{Conflict of Interest}

No potential conflict of interest relevant to this article was reported.

\section{Author Contributions}

Conception and design: AA, BG, NM, VG; intellectual content: AA, BG, NM; literature search: AA, BG, NM, SS; data acquisition: AA, SS; data analysis and interpretation: AA, NM, SS, VG; manuscript writing: AA; manuscript preparation: $\mathrm{BG}$; manuscript editing and review: $\mathrm{AA}, \mathrm{BG}$, NM, SS, VG; statistical analysis: VG; and approval of final manuscript and agree to be accountable for all aspects of work: all authors.

\section{References}

1. World Health Organization. Global tuberculosis report 2019 [Internet]. Geneva: World Health Organization; 2019 [cited 2021 Jan 22]. Available from: https://apps.who.int/iris/bitstream/hand le/10665/329368/9789241565714-eng.pdf.

2. World Health Organization, Regional Office for South-East Asia. Tuberculosis control in the SouthEast Asia region: annual report 2016 [Internet]. Geneva: World Health Organization; 2016 [cited 2021 Jan 22]. Available from: https://apps.who.int/iris/ handle/10665/205286.

3. Teo HE, Peh WC. Skeletal tuberculosis in children. Pediatr Radiol 2004;34:853-60.

4. Polley P, Dunn R. Noncontiguous spinal tuberculosis: incidence and management. Eur Spine J 2009;18:1096-101.

5. Zumla A, Nahid P, Cole ST. Advances in the development of new tuberculosis drugs and treatment regimens. Nat Rev Drug Discov 2013;12:388-404.

6. Ge Z, Wang Z, Wei M. Measurement of the concentration of three antituberculosis drugs in the focus of spinal tuberculosis. Eur Spine J 2008;17:1482-7.

7. Novaes RD, Teixeira AL, de Miranda AS. Oxidative stress in microbial diseases: pathogen, host, and therapeutics. Oxid Med Cell Longev 2019;2019:8159562.

8. Tuli SM. Tuberculosis of the spine: a historical review. Clin Orthop Relat Res 2007;460:29-38.

9. Jain AK. Tuberculosis of the spine: a fresh look at an old disease. J Bone Joint Surg Br 2010;92:905-13.

10. Nene A, Bhojraj S. Results of nonsurgical treatment of thoracic spinal tuberculosis in adults. Spine J 2005;5:79-84.

11. Singh R, Magu NK, Rohilla RK. Clinicoradiologic profile of involvement and healing in tuberculosis of 
the spine. Ann Med Health Sci Res 2016;6:311-27.

12. Andronikou S, Jadwat S, Douis H. Patterns of disease on MRI in 53 children with tuberculous spondylitis and the role of gadolinium. Pediatr Radiol 2002;32:798-805.

13. Mittal S, Jain AK, Chakraborti KL, Aggarwal AN, Upreti L, Bhayana H. Evaluation of healed status in tuberculosis of spine by fluorodeoxyglucose-positron emission tomography/computed tomography and contrast magnetic resonance imaging. Indian J Orthop 2019;53:160-8.

14. Jullien S, Jain S, Ryan H, Ahuja V. Six-month therapy for abdominal tuberculosis. Cochrane Database Syst Rev 2016;11:CD012163.

15. Jullien S, Ryan H, Modi M, Bhatia R. Six months therapy for tuberculous meningitis. Cochrane Database Syst Rev 2016;9:CD012091.

16. Wang Z, Shi J, Geng G, Qiu H. Ultra-short-course chemotherapy for spinal tuberculosis: five years of observation. Eur Spine J 2013;22:274-81.

17. Nene AM, Patil S, Kathare AP, Nagad P, Nene A, Kapadia F. Six versus 12 months of anti tubercular therapy in patients with biopsy proven spinal tuberculosis: a single center, open labeled, prospective randomized clinical trial-a pilot study. Spine (Phila Pa 1976) 2019;44:E1-6.

18. Aryal A, Garg B. Duration of anti-tubercular chemotherapy in Pott's spine: a systematic review: PROSPERO 2020 CRD42020200938 [Internet]. London: National Institute for Health Research; 2020 [cited 2021 Jan 22]. Available from: https://www.crd.york.ac.uk/ prospero/display_record.php?RecordID=200938.

19. Abbas A, Rizvi SR, Mahesri M, Salahuddin HR. Conservative management of spinal tuberculosis: initial series from Pakistan. Asian Spine J 2013;7:73-80.

20. Bakhsh A. Medical management of spinal tuberculosis: an experience from Pakistan. Spine (Phila Pa 1976) 2010;35:E787-91.

21. Batirel A, Erdem H, Sengoz G, et al. The course of spinal tuberculosis (Pott disease): results of the multinational, multicentre Backbone-2 study. Clin Microbiol Infect 2015;21:P1008.

22. Bodapati PC, Vemula RC, Mohammad AA, Mohan A. Outcome and management of spinal tuberculosis according to severity at a tertiary referral center. Asian J Neurosurg 2017;12:441-6.

23. Cao G, Rao J, Cai Y, et al. Analysis of treatment and prognosis of 863 patients with spinal tuberculosis in Guizhou province. Biomed Res Int 2018;2018:3265735.

24. Guo LX, Ma YZ, Chen X, Bao D, Luo XB. Clinical study of short-course chemotherapy combined with radical operation in retreating spinal tuberculosis. Zhongguo Gu Shang 2010;23:491-4.

25. Jain AK, Srivastava A, Saini NS, Dhammi IK, Sreenivasan R, Kumar S. Efficacy of extended DOTS category I chemotherapy in spinal tuberculosis based on MRIbased healed status. Indian J Orthop 2012;46:633-9.

26. Jutte PC, van Loenhout-Rooyackers JH. Routine surgery in addition to chemotherapy for treating spinal tuberculosis. Cochrane Database Syst Rev 2006;(1):CD004532.

27. Karaeminogullari O, Aydinli U, Ozerdemoglu R, Ozturk C. Tuberculosis of the lumbar spine: outcomes after combined treatment of two-drug therapy and surgery. Orthopedics 2007;30:55-9.

28. Kotil K, Alan MS, Bilge T. Medical management of Pott disease in the thoracic and lumbar spine: a prospective clinical study. J Neurosurg Spine 2007;6:2228.

29. Moon MS, Kim I, Woo YK, Park YO. Conservative treatment of tuberculosis of the thoracic and lumbar spine in adults and children. Int Orthop 1987;11:31522.

30. Walker AS. A 15-year assessment of controlled trials of the management of tuberculosis of the spine in Korea and Hong Kong: thirteenth report of the Medical Research Council Working Party on Tuberculosis of the Spine. J Bone Joint Surg Br 1998;80:456-62.

31. Niu N, Wang Q, Shi J, et al. Clinical and genomic responses to ultra-short course chemotherapy in spinal tuberculosis. Exp Ther Med 2017;13:1681-8.

32. Parthasarathy R, Sriram K, Santha T, Prabhakar R, Somasundaram PR, Sivasubramanian S. Shortcourse chemotherapy for tuberculosis of the spine: a comparison between ambulant treatment and radical surgery: ten-year report. J Bone Joint Surg Br 1999;81:464-71.

33. Patankar AP. Tuberculosis of spine: an experience of 30 cases over two years. Asian J Neurosurg 2016;11:22631.

34. Patil SS, Mohite S, Varma R, Bhojraj SY, Nene AM. Non-surgical management of cord compression in tuberculosis: a series of surprises. Asian Spine J 2014;8:315-21. 
35. Qian J, Rijiepu A, Zhu B, Tian D, Chen L, Jing J. Outcomes of radical debridement versus no debridement for the treatment of thoracic and lumbar spinal tuberculosis. Int Orthop 2016;40:2081-8.

36. Rajasekaran S, Shanmugasundaram TK, Prabhakar R, Dheenadhayalan J, Shetty AP, Shetty DK. Tuberculous lesions of the lumbosacral region: a 15-year follow-up of patients treated by ambulant chemotherapy. Spine (Phila Pa 1976) 1998;23:1163-7.

37. Rajeswari R, Balasubramanian R, Venkatesan P, et al. Short-course chemotherapy in the treatment of Pott's paraplegia: report on five year follow-up. Int J Tuberc Lung Dis 1997;1:152-8.

38. Upadhyay SS, Saji MJ, Yau AC. Duration of antituberculosis chemotherapy in conjunction with radical surgery in the management of spinal tuberculosis. Spine (Phila Pa 1976) 1996;21:1898-903.

39. Valsalan R, Purushothaman R, Raveendran M, Zacharia B, Surendran S. Efficacy of directly observed treatment short-course intermittent regimen in spinal tuberculosis. Indian J Orthop 2012;46:138-44.

40. Wang Z, Ge Z, Jin W, et al. Treatment of spinal tuberculosis with ultrashort-course chemotherapy in conjunction with partial excision of pathologic vertebrae. Spine J 2007;7:671-81.

41. Wang XY, Luo CK, Li WW, et al. A practical therapeutic protocol for cervical tuberculosis. Eur J Trauma Emerg Surg 2013;39:93-9.

42. Wardak GM, Panezai H, Kakar RM. Efficacy of conservative management with anti tuberculosis treatment in patients with spinal tuberculosis. Pak J Neurol Surg 2014;18:156-61.

43. Wu QQ. Preliminary report of short-course tuberculosis of the spine. Zhonghua Jie He He Hu Xi Za Zhi 1990;13:160-1,191.

44. Zhang X, Ji J, Liu B. Management of spinal tuberculosis: a systematic review and meta-analysis. J Int Med Res 2013;41:1395-407.

45. Van Tulder M, Furlan A, Bombardier C, Bouter L; Editorial Board of the Cochrane Collaboration Back Review Group. Updated method guidelines for systematic reviews in the Cochrane collaboration back review group. Spine (Phila Pa 1976) 2003;28:1290-9.

46. A controlled trial of six-month and nine-month regimens of chemotherapy in patients undergoing radical surgery for tuberculosis of the spine in Hong Kong: tenth report of the Medical Research Council
Working Party on Tuberculosis of the Spine. Tubercle 1986;67:243-59.

47. Controlled trial of short-course regimens of chemotherapy in the ambulatory treatment of spinal tuberculosis: results at three years of a study in Korea: twelfth report of the Medical Research Council Working Party on Tuberculosis of the Spine. J Bone Joint Surg Br 1993;75:240-8.

48. Indian Council of Medical Research; British Medical Research Council Working Party. A controlled trial of short-course regimens of chemotherapy in patients receiving ambulatory treatment or undergoing radical surgery for tuberculosis of the spine. Indian J Tuberc 1989;36:1-21.

49. Banga RK, Singh J, Dahuja A, Garg RS. Spinal tuberculosis: directly observed treatment and short course or daily anti tubercular therapy: are we over treating? Open Orthop J 2018;12:380-8.

50. DerSimonian R, Laird N. Meta-analysis in clinical trials. Control Clin Trials 1986;7:177-88.

51. Harris RJ, Deeks JJ, Altman DG, Bradburn MJ, Harbord RM, Sterne JA. Metan: fixed-and randomeffects meta-analysis. Stata J 2008;8:3-28.

52. MRC Working Party on Tuberculosis of the Spine, Darbyshire J. Five-year assessment of controlled trials of short-course chemotherapy regimens of 6,9 or 18 months' duration for spinal tuberculosis in patients ambulatory from the start or undergoing radical surgery: fourteenth report of the Medical Research Council Working Party on Tuberculosis of the Spine. Int Orthop 1999;23:73-81.

53. Reetha AM, Sivasubramanian S, Parthasarathy R, Somasundaram PR, Prabhakar R. Five-year findings of a comparison of ambulatory short course chemotherapy with radical surgery plus chemotherapy for tuberculosis of the spine in Madras. Indian J Orthop 1994;28:7-13.

54. Higgins J, Thompson S, Deeks J, Altman D. Statistical heterogeneity in systematic reviews of clinical trials: a critical appraisal of guidelines and practice. J Health Serv Res Policy 2002;7:51-61.

55. Higgins JP, Thompson SG, Deeks JJ, Altman DG. Measuring inconsistency in meta-analyses. BMJ 2003;327:557-60.

56. Kumar K. Spinal tuberculosis, natural history of disease, classifications and principles of management with historical perspective. Eur J Orthop Surg Trau- 
matol 2016;26:551-8.

57. National Institute for Health and Care Excellence. Tuberculosis: NICE guidance: recommendations [Internet]. London: National Institute for Health and Care Excellence; 2016 [cited 2021 Feb 5]. Available from: https://www.nice.org.uk/guidance/ng33/chapter/recommendations.

58. Saeed K, Esposito S, Ascione T, et al. Hot topics on vertebral osteomyelitis from the International Society of Antimicrobial Chemotherapy. Int J Antimicrob Agents 2019;54:125-33.

59. Fisher D, Elwood K. Nonrespiratory tuberculosis. In: Fisher D, Elwood K, editors. Canadian tuberculosis standards 7th edition: 2014 [Internet]. Ottawa: Canadian Thoracic Society, Canadian Lung Association, Public Health Agency of Canada; 2014 [cited 2021 Feb 5]. Available from: https://www.canada.ca/en/ public-health/services/infectious-diseases/canadiantuberculosis-standards-7th-edition/edition-19.html.

60. Tins BJ, Cassar-Pullicino VN, Lalam RK. Magnetic resonance imaging of spinal infection. Top Magn Reson Imaging 2007;18:213-22.

61. Van Loenhout-Rooyackers JH, Verbeek AL, Jutte PC. Chemotherapeutic treatment for spinal tuberculosis. Int J Tuberc Lung Dis 2002;6:259-65. 